\title{
DIFFERENT RESPONSE PATTERNS OF FISH FOREGUT AND HINDGUT MICROBIOTA TO HOST HABITATS AND GENOTYPES
}

\author{
LI, J. J. ${ }^{*}-$ NI, J. J. ${ }^{2,3}-$ WANG, C. ${ }^{4}-$ YU, Y. H. ${ }^{5}-$ ZHANG, T. L. ${ }^{5}$ \\ ${ }^{1}$ School of life sciences, Qilu Normal University, Jinan 250200, China \\ (phone: +86-138-6417-3055; fax: +86-138-6417-3055) \\ ${ }^{2}$ Guangdong Meilikang Bio-Science Ltd., Dongguan 523000, China \\ ${ }^{3}$ Dongguan Key Laboratory of Medical Bioactive Molecular Developmental and Translational \\ Research, Guangdong Medical University, Dongguan 523808, China \\ ${ }^{4}$ Department of Environmental Science and Engineering, Beijing Technology and Business \\ University, Beijing 100048, China \\ ${ }^{5}$ Key Laboratory of Biodiversity and Conservation of Aquatic Organisms, Institute of \\ Hydrobiology, Chinese Academy of Sciences, Wuhan, China \\ *Corresponding author \\ e-mail: lijinjin0531@163.com
}

(Received $28^{\text {th }}$ May 2020; accepted $20^{\text {th }}$ Aug 2020)

\begin{abstract}
Fish gut microbiota can be affected by factors such as diet, habitat, and genotype. However, whether the foregut and hindgut microbiota respond similarly to these factors is still ambiguous. Given the fact that foregut has more communication with fish habitat and food intake, we hypothesized that the foregut microbiota is possibly more affected by external factors (e.g., habitat), while the hindgut microbiota tends to be mainly influenced by the host itself (e.g., genotype). To test our hypothesis, the V4 region of the gut bacterial 16S rRNA gene was amplified and sequenced by the MiSeq platform. A total of 1,139,703 high-quality sequences and 7,698 OTUs (without singlets) were obtained. Results indicated that the major factors that affect the fish gut microbiota patterns were the gut sections and habitats, rather than fish species. The foregut microbiota was indeed more similar to the water microbiota than hindgut microbiota, whereas the hindgut microbiota between fish species showed relatively more differences than that of foregut microbiota. Therefore, foregut and hindgut microbiota exhibited different response patterns to the habitat environments and host genotypes. This finding extended our understanding of the maintenance mechanism of fish gut microbial biodiversity.
\end{abstract}

Keywords: freshwater lake, gut microbiome, high-throughput sequencing, silver carp, bighead carp

\section{Introduction}

Gut microbiota not only assist their host in digesting food, but also help host to resist the invasion of pathogens (Stevens and Hume, 1998; Mountfort et al., 2002; Saha et al., 2006; Nicholson et al., 2005, 2012; Mardinoglu et al., 2015; Macpherson et al., 2018; Martens et al., 2018). Increasing evidence indicated that different gut positions were colonized by different microbiota (Eckburg et al., 2005; Ni et al., 2014a). Although it has been confirmed that many factors, such as diet, genotype, geography, lifestyle, and development of host (Ni et al., 2014b; Lloyd-Price et al., 2016; Yadav et al., 2016; Yan et al., 2016; Li et al., 2017; Ding et al., 2018), cast the composition and metabolism of gut microbiota, the influence degrees of these factors on gut microbiota at different gut positions are still ambiguous. Considering gut dysbiosis closely relates to host diseases 
(Martin et al., 2009; Nicholson et al., 2012; Lloyd-Price et al., 2016; Xiang et al., 2018; Huang et al., 2018; Ni et al., 2019), elucidating the influence of external and internal factors on the composition of gut microbiota will promote artificial regulation to the composition of gut microbiota and also can help the host to prevent some diseases.

Silver carp (Hypophthalmichthys molitrix, M.) and bighead carp (Hypophthalmichthys nobilis, N.) are important players in the biological network of freshwater ecosystems (Ni and Jiang, 1954; Xie, 2003). They are also major targets of aquaculture and are key protein resources in China. Previous studies showed that these species have different feeding preferences, i.e., silver carp and bighead carp are prefer to filter-feeding the phytoplankton and zooplankton, respectively (Ni and Jiang, 1954; Chen, 1982). In addition, comparing with hindgut, the foregut has more connection with the water environment, and foregut microbiota are more likely to be influenced by habitat.

Therefore, we hypothesized that the fish foregut microbiota was more possibly affected by external factors such as host habitats and diets, while the hindgut microbiota tend to be mainly influenced by host genotypes. To test the hypothesis, 16S rRNA genes of the foregut and hindgut microbiota of silver carp and bighead carp collected from different habitats (lake and pond) were analyzed using high-throughput sequencing. The finding of the present study would extended our understanding of the maintenance mechanism of fish gut microbial biodiversity.

\section{Materials and methods}

\section{Experimental design and sampling procedures}

Silver carp and bighead carp were collected from three freshwater lakes, i.e., Shangshe Lake (S, 30 $\left.0^{\circ}-30^{\circ} 9^{\prime} \mathrm{N}, 114^{\circ} 11.5^{\prime}-114^{\circ} 16.5^{\prime} \mathrm{E}\right)$, Wuhu Lake (W, 30 $47^{\prime}-30^{\circ} 50^{\prime} \mathrm{N}$, $\left.114^{\circ} 28^{\prime}-114^{\circ} 33^{\prime} \mathrm{E}\right)$, and Niushan Lake (N, 30 $\left.16^{\prime}-30^{\circ} 22^{\prime} \mathrm{N}, 114^{\circ} 27^{\prime}-114^{\circ} 38^{\prime} \mathrm{E}\right)$, and two freshwater ponds in China under different environmental conditions (Fig. 1). The experimental lakes are all shallow-water freshwater lakes in the middle reaches of the Yangtze River, with complex freshwater biological communities and high biological productivity. The lake is less polluted, and the utilization method is mainly fishery development. Niushan Lake belongs to the Liangzi Lake water system, with a water area of $40 \mathrm{~km}^{2}$. The existing area of Shangshe Lake and Wuhu Lake is $11.9 \mathrm{~km}^{2}$ and $21.2 \mathrm{~km}^{2}$, respectively. The two ponds are artificially stocked and managed aquaculture water bodies which located on the south bank of Liangzi Lake $\left(30^{\circ} 04^{\prime}-30^{\circ} 20^{\prime} \mathrm{N}, 114^{\circ} 31^{\prime}-\right.$ $114^{\circ} 42^{\prime}$ E). Sampling was performed in May 2013. Three individuals of each species were randomly selected in each site with the exception of Niushan Lake, in which only one silver carp and three bighead carp were catched, and then immediately transported to the laboratory with in situ water. The fish body was cleaned with $70 \%$ alcohol and anatomized according to a previously described method (Ni et al., 2014b). About $0.5 \mathrm{~g}$ of the gut contents from the foregut and hindgut were aseptically extracted and then stored at $-20{ }^{\circ} \mathrm{C}$ for downstream DNA extraction. Water samples from the three lakes and two ponds (i.e., Shangshe Lake-SW, Wuhu Lake-WW, Niushan Lake-NW, Pond I-PIW, and Pond II-PIIW) were also collected for environmental microbiota analysis. About $500 \mathrm{~mL}$ of each water was first filtered with a $1.2-\mu \mathrm{m}$ glass-fiber $(\mathrm{GF} / \mathrm{C})$ filter and then with a $0.22-\mu \mathrm{m}$ filter to collect microbes for DNA extraction.

All experiments involving animals were performed under the protocols approved by the Institutional Animal Care and Use Committee of Institute of Hydrobiology, Chinese Academy of Sciences (Approval ID: keshuizhuan 08529). 


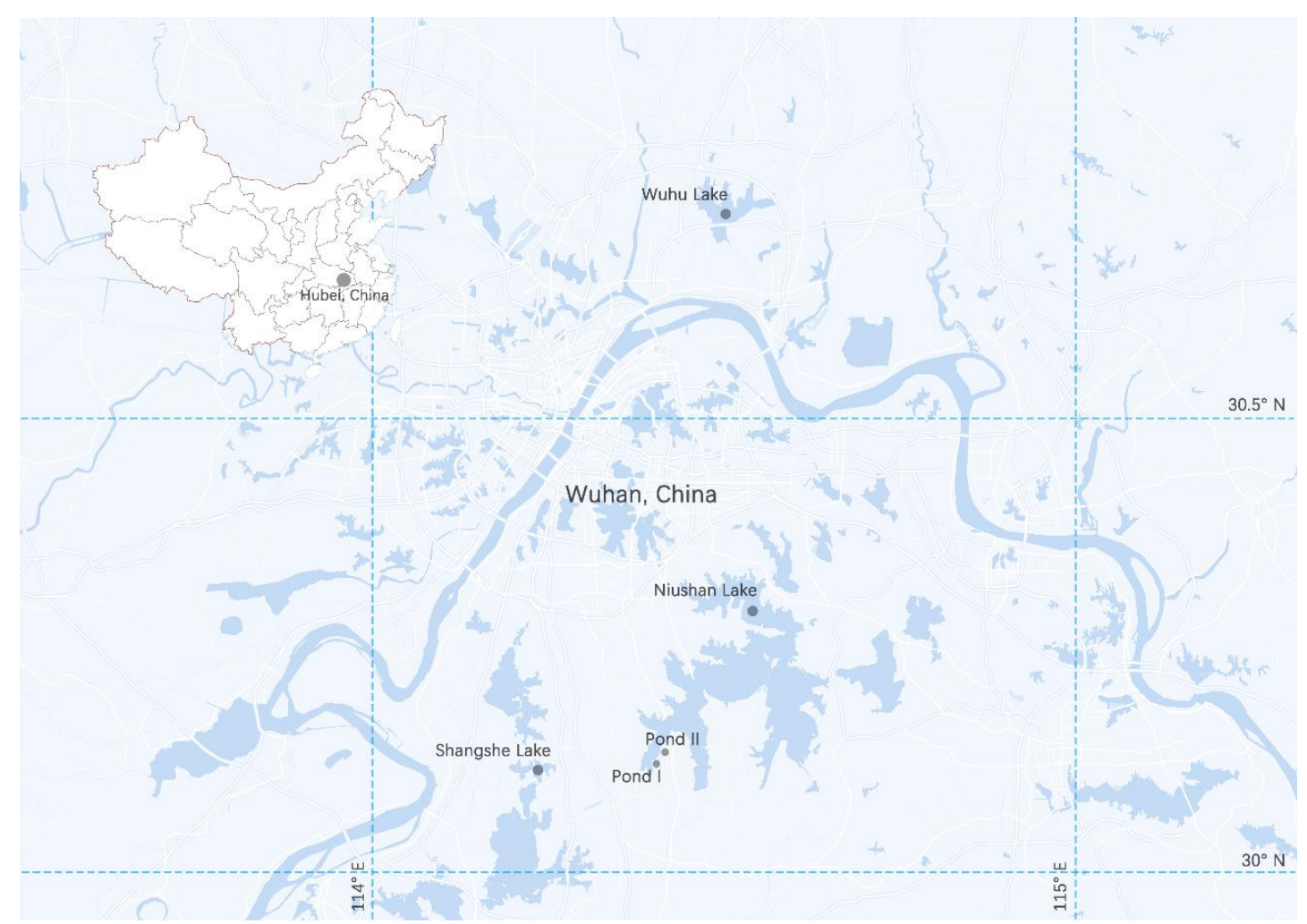

Figure 1. Map shows the locations of sampling lakes and ponds

\section{DNA extraction and high-throughput sequencing}

Genomic DNA of the gut microbiota was extracted from approximately $0.5 \mathrm{~g}$ of gut contents using a PowerFecal ${ }^{\circledR}$ DNA isolation kit (MoBio, CA, USA) according to the manufacturer's instructions. Genomic DNA of the habitat water microbiota was extracted from the filter membranes using the PowerFecal ${ }^{\circledR}$ DNA isolation kit (MoBio, CA, USA) too. DNA concentration was determined by a NanoDrop ND-1000 and then diluted to the same concentration $(2 \mathrm{ng} / \mu \mathrm{L})$ for subsequent PCR amplification. The V4 region of the bacterial 16S rRNA gene was amplified using 515F and 806R primers to compare the gut microbiota as our previous description (Yan et al., 2016). The PCR products were visualized using $1 \%$ agarose gels stained with ethidium bromide. The successfully amplified PCR products were quantified using a PicoGreen dsDNA assay kit (Invitrogen, CA, USA). The products of each sample were equally combined and then subjected to gel purification. The purified DNA was re-quantified using the PicoGreen dsDNA assay kit, and the DNA library was applied for sequencing on the MiSeq platform according to the manufacturer's instructions.

The MiSeq reads were qualitatively filtered and processed with the Galaxy pipeline (http://zhoulab5.rccc.ou.edu:8080/root). After trimming the primer and deleting the sequences that contain $\mathrm{N}$, the sequences with lengths of 245-260 bp were retained for subsequent analysis. The OTUs were generated by UCLUST clustering method with $97 \%$ sequence similarity. Then singlets were removed from further analysis. To exclude the interference of sequencing depth on the absolute abundance of each OTU, the relative abundance of each OTU was used in further analysis. 


\section{Data analysis}

The UPGMA clustering was performed using the software XLSTAT 7.5.2. Redundancy analysis (RDA), principal component analysis (PCA), and non-parametric multivariate analysis of variance (PERMANOVA) were conducted using vegan package (Dixon, 2003) in R version 3.0.1 (R Core Team, 2017).

\section{Results}

A total of $1,139,703(18684 \pm 3720$, mean \pm S.E. $)$ high-quality sequences and 7,698 OTUs $(619 \pm 360)$ without singlets were obtained from the foregut and hindgut samples of silver carp and bighead carp, and the habitat water. Excepting a small part $(2.86 \pm 3.29 \%)$ of sequences could not be classified into any phylum, a total of 7,667 bacteria OTUs were categorized into 23 phyla, whereas 9 OTUs were attributed to archaea (Euryarchaeota or Crenarchaeota). Bacteroidetes primarily appeared in hindgut microbiota of lake fishes. Cyanobacteria primarily appeared in the foregut microbiota of lake fishes and freshwater. Fusobacteria primarily appeared in gut microbiota of pond fishes and hindgut microbiota of lake fishes (Fig. 2). UPGMA clustering showed that freshwater microbiota embedded the branch of foregut microbiota (Fig. 2). This result showed that the freshwater microbiota were more similar with foregut microbiota of the fishes.

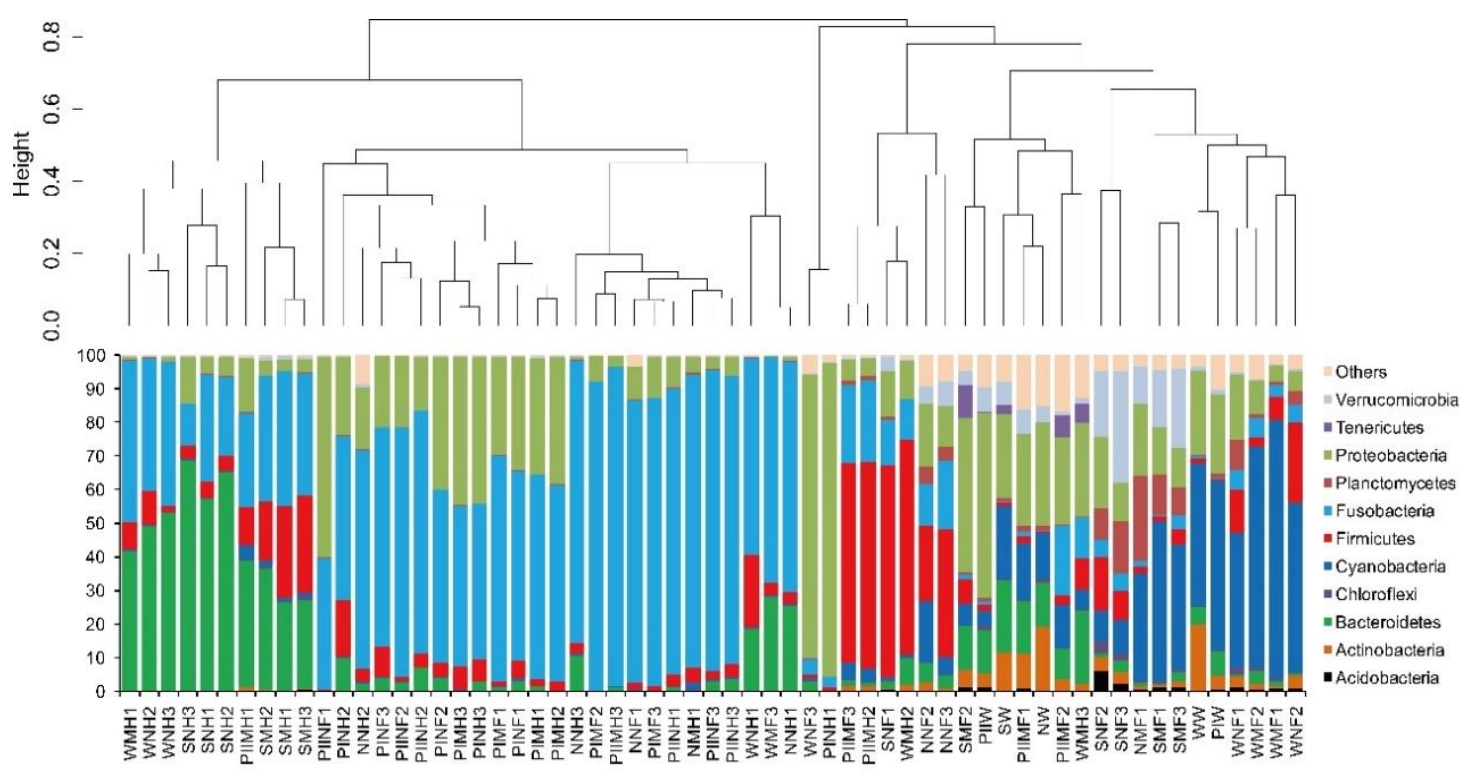

Figure 2. Dominant phyla of gut and pond water microbiota. SM: the gut microbiota of silver carp collected from Shangshe Lake; SN: the gut microbiota of bighead carp collected from Shangshe Lake; WM: the gut microbiota of silver carp collected from Wuhu Lake; WN: the gut microbiota of bighead carp sampled from Wuhu Lake; NM: the gut microbiota of silver carp sampled from Niushan Lake; NN: the gut microbiota of bighead carp sampled from Niushan Lake. PIM: the gut microbiota of silver carp sampled from pond I; PIN: the gut microbiota of bighead carp sampled from pond I; PIIM: the gut microbiota of silver carp sampled from pond II; PIIN: the gut microbiota of bighead carp sampled from pond II. In the last lowercases of the sampled names, $F$ denotes that the samples were obtained from the foreguts and $H$ represents the samples from the hindguts 
At OTU level, the result of RDA revealed that the gut microbiota clustered according to gut sections (i.e., foregut or hindgut) and habitats (i.e. lake or pond) rather than fish species (Fig. 3A). Although neither foregut nor hindgut microbiota of fishes were separated according to the fish species (MNAOVA, $p=0.24$ for foregut; and $p=0.09$ for hindgut), both foregut microbiota (MNAOVA, $\mathrm{p}=0.005$ ) and hindgut microbiota (MNAOVA, $\mathrm{p}=0.005$ ) were separated from each lake and each pond (Fig. 3B,C). Excluding the influence of habitat, only the foregut microbiota of Pond II fishes (MNAOVA, $\mathrm{p}=0.005$ ) and the hindgut microbiota of Shangshe Lake fishes (MNAOVA, $\mathrm{p}=0.005$ ) were significantly separated from silver carp and bighead carp. In addition, the hindgut microbiota of Wuhu Lake (MNAOVA, $\mathrm{p}=0.06$ ) and Pond I fishes (MNAOVA, $\mathrm{p}=0.08$ ) were significant differences between silver carp and bighead carp. These results implied that the hindgut microbiota easier separated according to fish species. For the fishes living in the lakes, their foregut tend to cluster together, whereas their hindgut tend to separated according to the fish species and lake (Fig. 3D). However, those trends was not true in the gut microbiota from pond fishes (Fig. 3E).
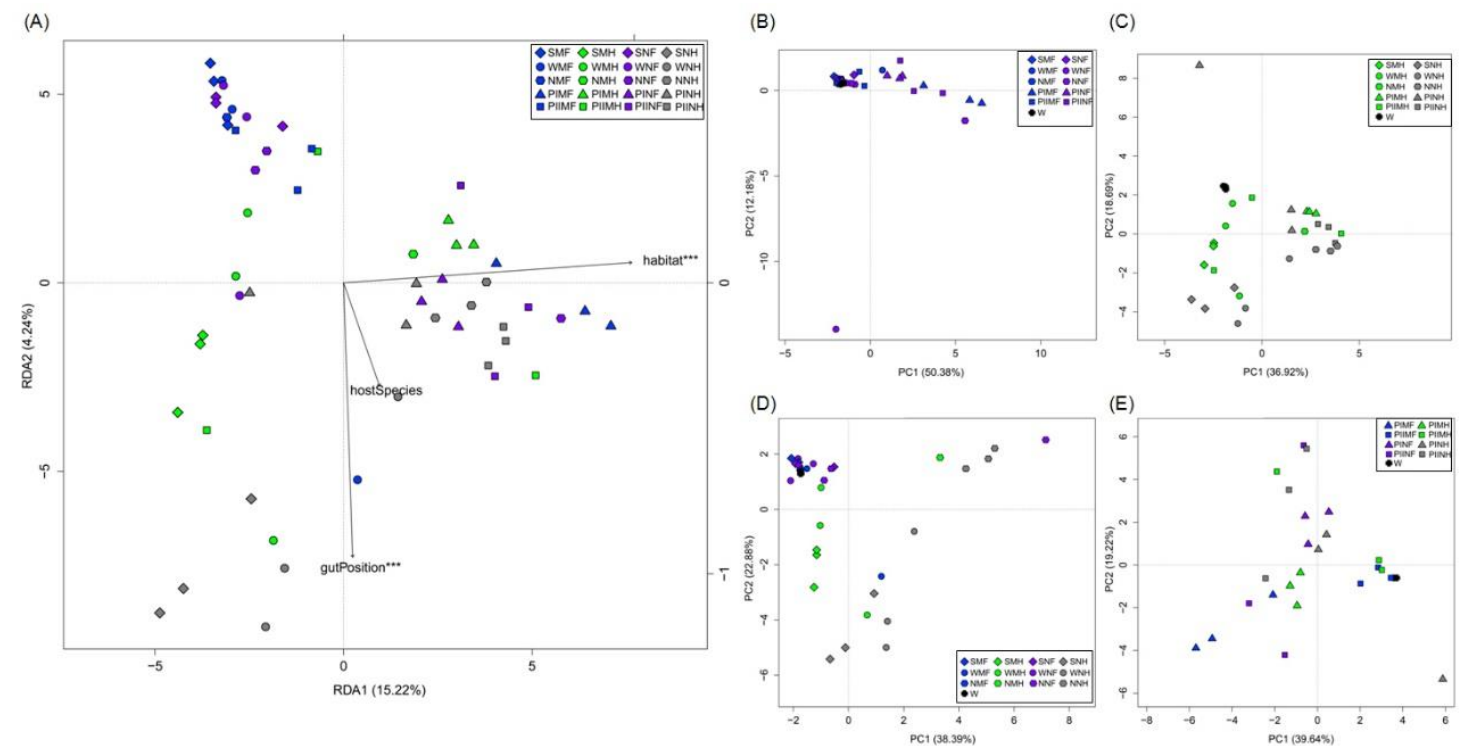

Figure 3. RDA profiles of microbiota from fish guts and freshwater. SM: the gut microbiota of silver carp sample from Shangshe Lake; SN: the gut microbiota of bighead carp sample from Shangshe Lake; WM: the gut microbiota of silver carp sample from Wuhu Lake; WN: the gut microbiota of bighead carp sample from Wuhu Lake; NM: the gut microbiota of silver carp sample from Niushan Lake; NN: the gut microbiota of bighead carp sample from Niushan Lake. PIM: the gut microbiota of silver carp sampled from pond I; PIN: the gut microbiota of bighead carp sampled from pond I; PIIM: the gut microbiota of silver carp sampled from pond II; PIIN: the gut microbiota of bighead carp sampled from pond II. In the last lowercases of the sample names, $F$ denotes that the samples were obtained from the foreguts and $H$ represents the samples from the hindguts. W: the water microbiota of lakes and ponds. $* p<0.05, * * p<$ 0.01 , and $* * * p<0.001$

Heatmap and clustering based on the dominant OTUs compositions of microbiota revealed that almost all of the gut microbiota of pond fishes were clustered into a clade. However, the foregut microbiota of lake fishes were separated from hindgut microbiota, only with individual outliers (Fig. 4). This indicated that the gut microbiota differentiation 
of silver carp and bighead carp was decreased under artificial pond culturing condition. Similar to the UPGMA clustering based on the dominant phyla of the microbiota, water microbiota embedded the branch of foregut microbiota (Fig. 4). An OTU of Cetobacterium was enriched in the gut microbiota of pond fishes. However, other OTUs of Cetobacterium was enriched in the hindgut microbiota of lake fishes (Fig. 4).

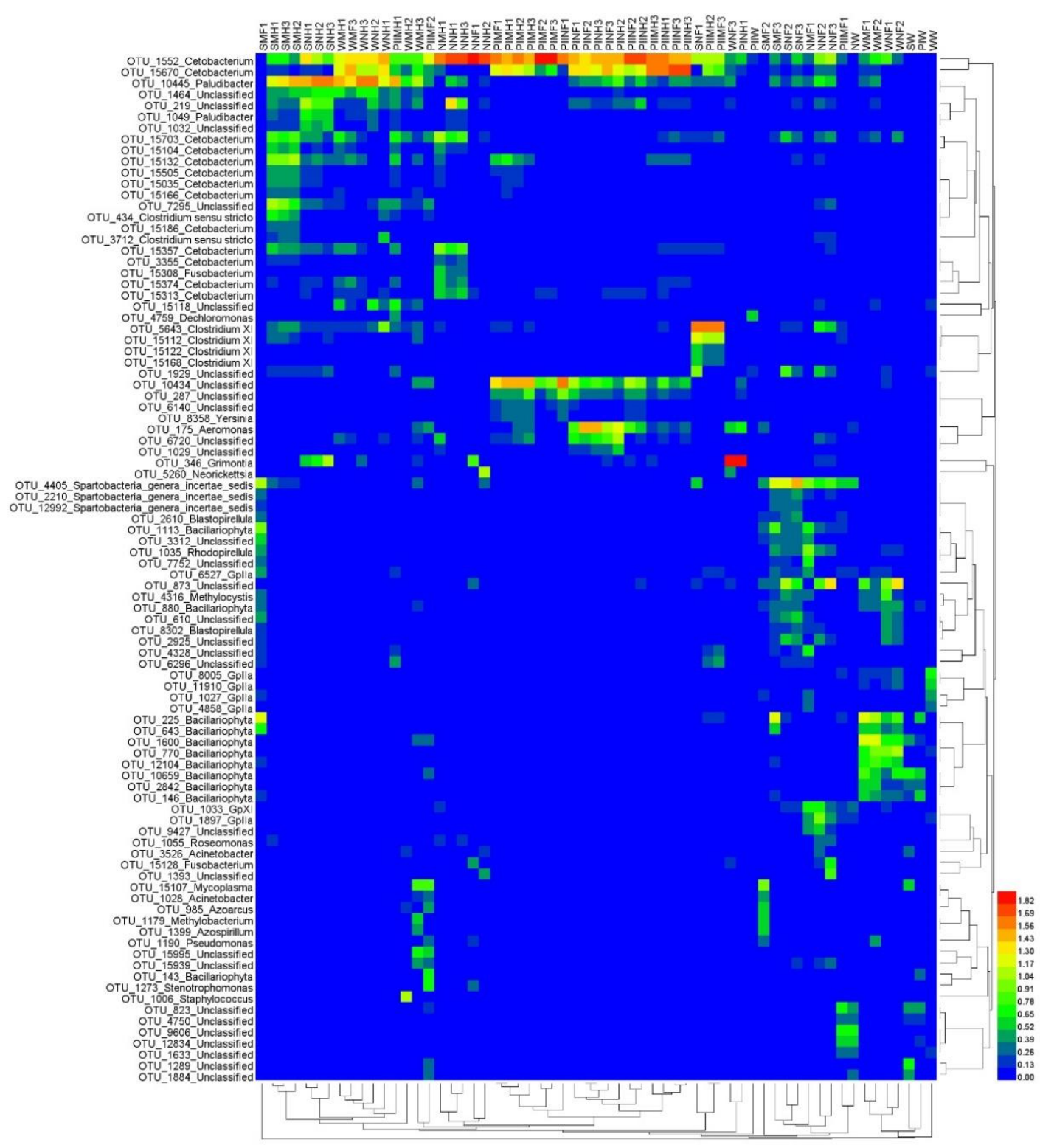

Figure 4. Heatmap profile showed the changes of dominant OTUs. SM: the gut microbiota of silver carp sample from Shangshe Lake; SN: the gut microbiota of bighead carp sample from Shangshe Lake; WM: the gut microbiota of silver carp sample from Wuhu Lake; WN: the gut microbiota of bighead carp sample from Wuhu Lake; NM: the gut microbiota of silver carp sample from Niushan Lake; NN: the gut microbiota of bighead carp sample from Niushan Lake. PIM: the gut microbiota of silver carp sampled from pond I; PIN: the gut microbiota of bighead carp sampled from pond I; PIIM: the gut microbiota of silver carp sampled from pond II; PIIN: the gut microbiota of bighead carp sampled from pond II. In the last lowercases of the sample names, $F$ denotes that the samples were obtained from the foreguts and $H$ represents the samples from the hindguts 


\section{Discussion}

Fish gut microbiota is significantly affected by various factors, such as gut position (Eckburg et al., 2005; Ni et al., 2014a), diet (Ley et al., 2008; Muegge et al., 2011), and habitat (Ni et al., 2014b). In the present study, we found the gut positions (foregut or hindgut) and host habitats (lake or pond) significantly affected the gut microbiota of silver carp and bighead carp (Fig. 3A). This indicated that microbiota formed independent communities in the foregut and hindgut of silver carp and bighead carp, it is consistent with previous studies (Eckburg et al., 2005; Ni et al., 2014a). The differences of microbiota at different gut positions probably caused by the differences of external and internal environments at different gut positions. The foregut is closer to fish mouth and its microbiota was probably easier impacted by external environmental factors of host, such as diet compositions, habitat environments, and some other unexpected factors. Simultaneously, the foregut microbiota would more similarly with habitat water microbiota, as shown in the present study (Fig. 2 and Fig. 4). However, the hindgut is far from fish mouth and its microbiota was probably affected by internal factors, such as host health, and host genotype. Therefore, the hindgut microbiota was generally separated according to the fish species as showed in the present study (Fig. 3B,C).

Geographic isolation is the major factor that restricts the spread of microorganisms and causes the distance-decay relationship (Green et al., 2004; Green and Bohannan, 2006; Ni et al., 2014a). Geographic differences in gut microbiota were reported in human (Escobar et al., 2014; Shin et al., 2016; He et al., 2018) and fish (Ni et al., 2014b). Our results showed that the gut microbiota of the fishes differed from their living habitats. This result indicated that the effect of geographic isolation not only affect the freshwater microbiota, but also showed important impacts on the gut microbiota of fishes living in the freshwater.

Previous studies that used classical morphological methods to identify food contents indicated silver carp mainly feeds on phytoplankton, and bighead carp prefer to the zooplankton (Ni and Jiang, 1954; Chen, 1982). Host diet is an important factor that affects the compositions of gut microbiota (Heavey and Rowland, 1999; Savas et al., 2005; Ley et al., 2008; Ward et al., 2009; Muegge et al., 2011; Tims et al., 2011; Walker et al., 2011). $\mathrm{Wu}$ et al. (2012) found that the core bacteria of the herbivorous grass carp include Proteobacteria, Firmicutes, and Actinobacteria. Wu et al. (2010) indicated that the dominant phyla of the carnivorous yellow carp are Proteobacteria, Fusobacteria, and Bacteroidetes. Li et al. (2012) reported that the dominant phyla of omnivorous common carp are Proteobacteria and Fusobacteria. These studies implied that the dominant microbiota phyla are affected by host diet. However, the present study did not show feeding habit resulted in different hindgut microbiota between silver carp and bighead carp. This inconsistency may be caused by one or more factors, such as substantial overlapping of their feeding, and disturbance of other unexpected factors on gut microbiota.

\section{Conclusion}

In conclusion, gut sections (i.e., foregut or hindgut) and habitats (i.e., lake or pond) rather than fish species were the major factors that can significantly affeced the gut microbitoa of silver carp and bighead carp. The foregut microbiota would more similarly with habitat water microbiota, and the hindgut microbiota was easer separated according to the fish species than foregut microbiota. Therefore, there have different response 
patterns of foregut and hindgut microbiota to habitat environments and host genotypes. Although the finding extended our understanding of the maintenance mechanism of fish gut microbial diversity, the function of the microbial diversity and the function and inflencing factors of each component of the gut microbiota still need to further study.

Acknowledgements. Our study was supported by the National Natural Science Foundation of China (31500417; 31700787), and the China Postdoctoral Science Foundation (2017M612691).

\section{REFERENCES}

[1] Chen, S. L. (1982): Feeding habits analysis of silver carp and bighead carp stocking in Lake Wuhu. - Reservoir fishery 3: 21-26.

[2] Ding, Q. W., Zhang, Z., Ran, C., He, S. X., Yang, Y. L., Du, Z. Y., Zhang, J. X., Zhou, Z. G. (2018): The hepatotoxicity of palmitic acid in zebrafish involves the intestinal microbiota. - Journal of Nutrition 148: 1217-1228.

[3] Dixon, P. (2003): VEGAN, a package of R functions for community ecology. - Journal of Vegetation Science 14(6): 927-930.

[4] Eckburg, P. B., Bik, E. M., Bernstein, C. N., Purdom, E., Dethlefsen, L., Sargent, M., Gill, S. R., Nelson, K. E., Relman, D. A. (2005): Diversity of the human intestinal microbial flora. - Science 308: 1635-1638.

[5] Escobar, J. S., Klotz, B., Valdes, B. E., Agudelo, G. M. (2014): The gut microbiota of Colombians differs from that of Americans, Europeans and Asians. - BMC Microbiology 14: 311 .

[6] Green, J. L., Holmes, A. J., Westoby, M., Oliver, I., Briscoe, D., Dangerfield, M., Gillings, M., Beattie, A. J. (2004): Spatial scaling of microbial eukaryote diversity. - Nature 432: 747-750.

[7] Green, J., Bohannan, B. J. M. (2006): Spatial scaling of microbial biodiversity. - Trends in Ecology and Evolution 21: 501-507.

[8] He, Y., Wu, W., Zheng, H.-M., Li, P., McDonald, D., Sheng, H.-F., Chen, M.-X., Chen, Z.-H., Ji, G.-Y., Zheng, Z.-D.-X., Mujagond, P., Chen, X.-J., Rong, Z.-H., Chen, P., Lyu, L.-Y., Wang, X., Wu, C.-B., Yu, N., Xu, Y.-J., Yin, J., Raes, J., Knight, R., Ma, W.-J., Zhou, H.-W. (2018): Regional variation limits applications of healthy gut microbiome reference ranges and disease models. - Nature Medicine 24: 1532-1535.

[9] Heavey, P. M., Rowland, I. R. (1999): The gut microflora of the developing infant: microbiology and metabolism. - Microbial Ecology in Health and Disease 11: 75-83.

[10] Huang, R., Li, T., Ni, J., Bai, X., Gao, Y., Li, Y., Zhang, P., Gong, Y. (2018): Different sex-based responses of gut microbiota during the development of hepatocellular carcinoma in liver-specific Tsc1-knockout mice. - Frontiers in Microbiology 9: 1008.

[11] Ley, R. E., Hamady, M., Lozupone, C., Turnbaugh, P. J., Ramey, R. R., Bircher, J. S., Schlegel, M. L., Tucker, T. A., Schrenzel, M. D., Knight, R., Gordon, J. I. (2008): Evolution of mammals and their gut microbes. - Science 320: 1647-1651.

[12] Li, X. M., Yu, Y. H., Feng, W. S., Yan, Q. Y., Gong, Y. C. (2012): Host species as a strong determinant of the intestinal microbiota of fish larvae. - Journal of Microbiology 50: 2937.

[13] Li, X. H., Zhou, L., Yu, Y. H., Ni, J. J., Xu, W. J., Yan, Q. Y. (2017): Composition of gut microbiota in the gibel carp (Carassius auratus gibelio) varies with host development. Microbial Ecology 74: 239-249.

[14] Lloyd-Price, J., Abu-Ali, G., Huttenhower, C. (2016): The healthy human microbiome. Genome Medicine 8: 51.

[15] Macpherson, A. J., Yilmaz, B. (2018): Antibodies that ilgAte our intestinal microbes. Science immunology 3(3): eaat4037. 
[16] Mardinoglu, A., Shoaie, S., Bergentall, M., Ghaffari, P., Zhang, C., Larsson, E., Bäckhed, F., Nielsen, J. (2015): The gut microbiota modulates host amino acid and glutathione metabolism in mice. - Molecular Systems Biology 11: 834.

[17] Martens, E. C., Neumann, M., Desai, M. S. (2018): Interactions of commensal and pathogenic microorganisms with the intestinal mucosal barrier. - Nature Reviews Microbiology 16: 457-470. DOI: 10.1038/s41579-018-0036-x.

[18] Martin, F. J., Sprenger, N., Yap, I. K. S., Wang, Y., Bibiloni, R., Rochat, F., Rezzi, S., Cherbut, C., Kochhar, S., Lindon, J. C., Holmes, E., Nicholson, J. K. (2009): Panorganismal gut microbiome-host metabolic crosstalk. - Journal of Proteome Research 8: 2090-2105.

[19] Mountfort, D. O., Campbell, J., Clements, K. D. (2002): Hindgut fermentation in three species of marine herbivorous fish. - Applied and Environmental Microbiology 68: 13741380.

[20] Muegge, B. D., Kuczynski, J., Knights, D., Clemente, J. C., Gonzalez, A., Fontana, L., Henrissat, B., Knight, R., Gordon, J. I. (2011): Diet drives convergence in gut microbiome functions across mammalian phylogeny and within humans. - Science 332: 970-974.

[21] Ni, D. S., Jiang, Y. Z. (1954): Issues regarding the diet of silver carp and bighead carp. Current Zoology 6: 59-71.

[22] Ni, J., Yan, Q., Yu, Y. H., Zhang, T. L. (2014a): Fish gut microecosystem: a model for detecting spatial pattern of microorganisms. - Chinese Journal of Oceanology and Limnology 32: 54-57.

[23] Ni, J. J., Yan, Q. Y., Yu, Y. H., Zhang, T. L. (2014b): Factors influencing the grass carp gut microbiome and its effect on metabolism. - FEMS Microbiology Ecology 87: 704-014.

[24] Ni, J., Huang, R., Zhou, H., Xu, X., Li, Y., Cao, P., Zhong, K., Ge, M., Chen, X., Hou, B., Yu, M., Peng, B., Li, Q., Zhang, P., Gao, Y. (2019): Analysis of the relationship between the degree of dysbiosis in gut microbiota and prognosis at different stages of primary hepatocellular carcinoma. - Frontiers in Microbiology 10: 1458.

[25] Nicholson, J. K., Holmes, E., Wilson, I. D. (2005): Gut microorganisms, mammalian metabolism and personalized health care. - Nature Reviews Microbiology 3: 431-438.

[26] Nicholson, J. K., Holmes, E., Kinross, J., Burcelin, R., Gibson, G., Jia, W., Pettersson, S. (2012): Host-gut microbiota metabolic interactions. - Science 336: 1262-1267.

[27] R Core Team (2017): R-A Language and Environment for Statistical Computing. - R Foundation for Statistical Computing. R version 3.4.3, Vienna.

[28] Saha, S., Roy, R. N., Sen, S. K., Ray, A. K. (2006): Characterization of cellulose-producing bacteria from the digestive tract of tilapia, Oreochromis mossambica (Peters) and grass carp, Ctenopharyngodon idella (Valenciennes). - Aquaculture Research 37: 380-388.

[29] Savas, S., Kubilay, A., Basmaz, N. (2005): Effect of bacterial load in feeds on intestinal microflora of seabream (Sparus aurata) larvae and juveniles. - Israeli Journal of Aquaculture-Bamidgeh 571: 3-9.

[30] Shin, J., Sim, M., Lee, J., Shin, D. (2016): Lifestyle and geographic insights into the distinct gut microbiota in elderly women from two different geographic locations. - Journal of Physiological Anthropology 35: 31.

[31] Stevens, C. E., Hume, I. D. (1998): Contributions of microbes in vertebrate gastrointestinal tract to production and conservation of nutrients. - Physiological Reviews 78: 393-427.

[32] Tims, S., Zoetendal, E. G., de Vos, W. M., Kleerebezem, M. (2011): Host genotype and the effect on microbial communities. - In: Nelson, K. E. (ed.) Metagenomics of the Human Body. New York: Springer Science + Business Media.

[33] Walker, A. W., Ince, J., Duncan, S. H., Webster, L. M., Holtrop, G., Ze, X. L., Brown, D., Stares, M. D., Scott, P., Bergerat, A., Louis, P., Mcintosh, F., Johnstone, A. M., Lobley, G. E., Parkhill, J., Flint, H. J. (2011): Dominant and diet-responsive groups of bacteria within the human colonic microbiota. - The ISME Journal 5: 220-230. 
[34] Ward, N. L., Steven, B., Penn, K., Methé, B. A., Detrich, W. H. (2009): Characterization of the intestinal microbiota of two Antarctic notothenioid fish species. - Extremophiles 13: 679-685.

[35] Wu, S. G., Gao, T. H., Zheng, Y. Z., Wang, W. W., Cheng, Y. Y., Wang, G. T. (2010): Microbial diversity of intestinal contents and mucus in yellow catfish (Pelteobagrus fulvidraco). - Aquaculture 303: 1-7.

[36] Wu, S. G., Wang, G. T., Angert, E. R., Wang, W. W., Li, W. X., Zou, H. (2012): Composition, diversity, and origin of the bacterial community in grass carp (Ctenopharyngodon idellus) intestine. - PLoS One 7: e30440.

[37] Xiang, J., He, T., Wang, P., Xie, M., Xiang, J., Ni, J. (2018): Opportunistic pathogens are abundant in the gut of cultured giant spiny frog (Paa spinosa). - Aquaculture Research 49: 2033-2041.

[38] Xie, P. (2003): Silver carp and bighead and cyanobacterial blooms control. - Peking: Science Press.

[39] Yadav, D., Ghosh, T. S., Mande, S. S. (2016): Global investigation of composition and interaction networks in gut microbiomes of individuals belonging to diverse geographies and age-groups. - Gut Pathogens 8: 17.

[40] Yan, Q. Y., Li, J. J., Yu, Y. H., Wang, J. J., He, Z. L., Joy, D., Van, N., Kempher, M. L., Wu, L. Y., Wang, Y. P., Liao, L. J., Li, X. H., Wu, S., Ni, J. J., Wang, C., Zhou, J. Z. (2016): Environmental filtering decreases with fish development for the assembly of gut microbiota. - Environmental Microbiology 18(2): 4739-4754. 